\title{
Effect of three extinction procedures following avoidance conditioning in preschool children*
}

\author{
GENE H. MOFFAT \\ University of Southern Mississippi, Hattiesburg, Mississippi 39401 \\ and \\ WILLIAM McGOWN \\ Eastern Illinois University, Charleston, Illinois 61920
}

\begin{abstract}
Following acquisition of an instrumental avoidance response, 36 preschool Ss were given 200 extinction trials. Omission of children's songs served as the aversive event. Three extinction procedures were established: (a) a CS-only procedure in which the music was never omitted, (b) $\dot{a}$ punishment procedure in which music omission was response contingent, and (c) a procedure whereby music omission was unavoidable and inescapable. The results were dependent upon the extinction procedures being compared; however, the CS-only procedure was most resistant to ex tinction.
\end{abstract}

The most commonly used procedure for extinguishing avoidance responses consists of presenting the warning signal (CS) while withholding the aversive stimulus (US) which had been associated with it during acquisition. However, Davenport and Olson (1968) argued that a more appropriate procedure would be to make the US unavoidable and the CS inescapable until the US occurred, since the reinforcing event in acquiring an avoidance response is presumed to be the escape of the CS and/or omission of the US. Using this procedure, Davenport and Olson (1968) reported rapid and reliable decreases in avoidance responding in rats. Hartley (1968) compared two unavoidable and inescapable US procedures (UI) with the typical CS-only extinction procedure in rats. No significant differences were reported between the two UI procedures. Ss in both UI groups extinguished significantly faster than Ss in the CS-only group. Bolles, Moot, and Grossen (1971) investigated CS-only, punishment, and two UI procedures in the extinction of shuttlebox avoidance in rats. Extinction occurred most readily when Ss acquired an effective alternative response to avoid shock (i.e., punishment). When all behaviors avoided shock (i.e., CS-only), avoidance was extremely resistant to extinction. When Ss continued to receive unavoidable shock (i.e., UI procedures) avoidance responding fell to a level intermediate between the two other procedures.

Research comparing various extinction of avoidance responding in human Ss has not been extensive. Meyer (1970) investigated CS-only, punishment, and two UI extinction procedures in college Ss. A 6-sec-duration, 40-psi air blast behind the right ear served as the US. Meyer (1970) stated that the CS-only was the least effective and punishment was most effective in

\footnotetext{
*Reprint requests should be sent to the first author Department of Psychology, University of Southern Mississippi, Hattiesburg, Mississippi 39401.
}

extinguishing responding. The two UI procedures were moderately effective. The Meyer (1970) and Bolles et al (1971) experiments demonstrated a striking consistency for the relative effectiveness of the three extinction procedures in adult human and infrahuman Ss. However, neither study reported specific statistical comparisons between the various procedures. Recently, Moffat and Koch (1974) investigated punishment duration and delay in extinguishing avoidance responding in college Ss. The US consisted of omission of Bill Cosby recordings. The results indicated that while punishment duration did not differentially affect extinction performance, resistance to extinction was a direct function of the punishment delay intervals. Ss in a CS-only control group showed significantly greater resistance to extinction than punished Ss.

The purpose of the present experiment was to investigate the CS-only, punishment, and UI extinction procedures in preschool children, using omission of entertaining material as the aversive event. Omission of entertaining material had been effective in establishing avoidance responding in young children (Moffat, 1972; Moffat \& Miller, 1971). Moreover, the avoidance response, once acquired by young children, is highly resistant to extinction with the CS-only procedure (Moffat, 1972).

\section{METHOD}

\section{Subjects}

Ss were 18 boys and 18 girls enrolled in the Children's Laboratory of Learning at the University of Southern Mississippi. Ss' ages ranged from 59 to 80 months ( $\overline{\mathrm{X}} \mathrm{CA}=69.5$ months).

\footnotetext{
Apparatus

The apparatus consisted of a black wooden response box, $9 \mathrm{x}$ $17.5 \times 3$ in. A microswitch was mounted in the midline of the top surface of the box 4 in. from the edge nearest $\mathrm{S}$. A hinged 5
} 
Table 1

Dependent Measures for the Three Extinction Groups

\begin{tabular}{|c|c|c|c|}
\hline \multirow[b]{2}{*}{ Dependent Measures } & \multicolumn{3}{|c|}{ Groups } \\
\hline & $\mathrm{N}$ & $\mathbf{P}$ & UI \\
\hline Mean number of trials to acquisition criterion for all Ss & 13.33 & 15.50 & 16.42 \\
\hline Number of Ss extinguishing & 3 & 12 & 12 \\
\hline Mean number of trials to extinction criterion for all Ss & 163.83 & 60.92 & 105.00 \\
\hline Stanđard deviation & 64.76 & 49.70 & 39.52 \\
\hline Mean number of avoidance responses in extinction for all Ss & 152.08 & 45.17 & 79.08 \\
\hline Standard deviation & 69.38 & 48.49 & 42.31 \\
\hline
\end{tabular}

x 6.5 in. panel was placed over the microswitch. A $10-\mathrm{W}$ green light bulb was mounted in the midline $1 \mathrm{in}$. from the back edge of the top surface of the box.

Four Hunter decade interval timers and interconnecting circuitry controlled light duration, duration of music omission, interstimulus interval (ISI), and intertrial interval (ITI). A Lafayette timer was used to record response latencies. A Sony-Matic TC-105 tape recorder was modified so that during omission intervals the tape continued to play but without sound. The recorded material was presented to Ss through Superex headphones.

The recorded material was songs from children's albums appropriate for preschool Ss (RCA CAL-1017, 1038).

\section{Design}

A delay conditioning procedure was used during acquisition with light offset and music om ission occurring simultaneously. The maximum light duration and music omission intervals were 2 and $10 \mathrm{sec}$, respectively. The ITI, as measured from the termination of the music omission interval to light onset of the next trial, was a constant $10 \mathrm{sec}$. During the ITI, the recording played continuously. An avoidance response within the 2-sec ISI immediately terminated the light and prevented the occurrence of the music omission interval. An escape response during the omission interval immediately reinstated the music. A response during the ITI did not affect the intervals or response consequence on the subsequent trial.

Preceding the acquisition trials, six boys and six girls were assigned randomly to one of the three extinction procedures. One group received the CS-only procedure (Group N). The music was never omitted during testing. An avoidance response immediately terminated the light and initiated a constant $20-\mathbf{s e c}$ ITI. On nonresponse trials, the light terminated automatically after $2 \mathrm{sec}$ and the 20-sec ITI was instated. Ss in Group P received a punishment procedure in which an avoidance response immediately terminated the light and instated an inescapable 10 -sec omission interval. The 10 -sec ITI followed the omission interval. On nonresponse trials, the light terminated automatically after $2 \mathrm{sec}$ and the 20 -sec ITI was initiated. Ss in Group UI could neither terminate the light with an avoidance response nor prevent the occurrence of an unavoidable and inescapable omission interval. The 10 -sec ITI followed the omission interval. On nonresponse trials, these contingencies were maintained.

\section{Procedure}

Each S was tested individually in a normally illuminated room. The following instructions were given: "You will be listening to some music today. From time to time the music may stop. The music may stop after the green light that you see in front of you goes on. Remember, the green light will go on and then the music may stop. If you press on the panel when the green light is on, the music may not go off." E then placed the headphones on $\mathrm{S}$ and started the tape recorder. An acquisition criterion of 9 of 10 avoidance responses within 50 trials was adopted. Upon meeting this criterion, $\mathrm{S}$ was immediately administered 50 extinction trials according to one of the three extinction procedures. An extinction criterion of 9 of 10 nonresponse trials was adopted.

For Ss not ex tinguishing within 50 trials, a second session was given $24 \mathrm{~h}$ later. In the second session, acquisition trials were not administered. Ss were given these instructions: "You will be listening to some new music today. Let me put the headphones on you." Ss were administered 150 extinction trials under the same procedure as in the first session. The criterion of 9 of 10 nonresponse trials were maintained.

\section{RESULTS}

\section{Three Group Analyses}

Table 1 presents the dependent measures included in the present study in terms of the number of (a) trials to meet the acquisition criterion, (b) Ss extinguishing, (c) trials to meet the extinction criterion, and (d) avoidance responses made during extinction.

A one-way analysis of variance (Winer, 1971) performed on the acquisition criterion measure indicated no significant differences among extinction groups $(F<1)$.

A Fisher exact probability test (Siegel, 1956), comparing the number of Ss extinguishing in Groups $\mathrm{N}$ and $P$, yielded a significant difference $(p=0.013)$. Specifically, only three Ss extinguished in Group N, whereas all 12 Ss extinguished in Group P. Similarly, Groups N and UI differed significantly $(p=0.013)$.

The trials to extinction criterion measure was subjected to a one-way analysis of variance. The results indicated a significant difference between groups, $F(2,33)=10.69, p<.001$. A Tukey (a) post hoc comparison test indicated that Ss in Groups $\mathrm{P}$ and UI required significantly fewer trials to extinguish than Ss in Group N $(p<.05)$. Groups $P$ and UI did not differ significantly $(p>.05)$. A similar analysis of variance performed on the number of avoidance responses made during extinction yielded a significant difference between groups, $F(2,33)=11.60, p<.001$. The Tukey (a) test indicated that $\mathrm{Ss}$ in Groups $\mathrm{P}$ and UI made significantly fewer avoidance responses during extinction than Ss in Group N $(p<.05)$. Ss in Groups P and UI did not differ significantly $(p>.05)$.

\section{Two Group Analyses}

Due to the possibility of within-group nonnormality in the distribution of scores for Ss in Group N, separate Tukey (a) tests were performed on the trials to 
extinction criterion measure and the number of avoidance responses made during extinction for Ss in Groups $\mathrm{P}$ and UI. For the trials to extinction criterion measure, the results indicated that $S$ s in Group $P$ required significantly fewer trials to reach criterion than Ss in Group UI ( $p<.05)$. Ss in Groups $P$ and UI did not differ significantly in the manner of avoidance responses made during extinction $(\mathrm{p}>.05)$.

\section{DISCUSSION}

The present results indicated that an avoidance response acquired by preschool children when music omission served as the aversive event was quite resistant to extinction under the CS-only procedure. The extinction performance of Ss in the punishment and UI procedures as compared with Ss in the CS-only procedure was remarkably consistent with infrahuman (Bolles et al, 1971) and adult human research (Meyer, 1970) which involved physically noxious US presentations.

Although the present results support Meyer's (1970) and Bolles et al's (1971) statements concerning the rank-order effectiveness of the three procedures, interpretation of the present results should be made with reference to the extinction procedures included in the post hoc analyses. The nonnormality of within-cell variance in the CS-only procedure was considered to have been the contributing factor for the inconsistency between the results of the three-group and two-group comparisons of the punishment and UI procedures. The superiority of the punishment procedure over the UI procedure was reflected in the trials to extinction measure only in the two-group analysis.

If the avoidance contingency is responsible for a rapidly acquired avoidance response as Bolles (1970) suggested, then resistance to extinction may be interpreted to be a function of (a) the extent to which the avoidance contingency remains unchanged, and/or (b) the extent to which the experimental conditions present during acquisition and/or extinction facilitate or interfere with the acquisition of another contingency to prevent the US from occurring. In the CS-only extinction procedure, the experimental contingencies during acquisition are modified so that a second contingency (i.e., a nonresponse contingency) also can prevent the US from occurring. However, the avoidance contingency remains unchanged. The experimental conditions do not differentiate between avoidance responses and nonresponses as contingent sources of reinforcement and, thus, interfere with the acquisition of the nonresponse contingency. As a result, the avoidance contingency is maintained and resistance to extinction is quite high.

The UI and punishment procedures result in a discernible change in the avoidance contingency. In both procedures, an avoidance response no longer presents the occurrence of the US. In the UI procedure, the experimental conditions present during acquisition remain unchanged. However, neither an avoidance response nor a nonresponse will prevent the occurrence of the US. Seligman, Maier, and Solomon (1971) have indicated that experimental conditions may be arranged so that the termination, reduction, or prevention of the aversive stimulus is not differentially affected by the presence or absence of responding. The UI procedure provides for such a unique arrangement of the experimental conditions. The occurrence of the US is independent of the presence or absence of responding. Seligman et al (1971) have shown that prior uncontrollable shock interferes with subsequent escape/avoidance behavior. If an acquired noncontingent relationship interferes with the subsequent establishment of the avoidance contingency, then it is not unwarranted to assume that prior acquisition of the avoidance contingency would be a condition sufficient to interfere with the subsequent acquisition of the independent relationship which exists in the UI procedure. Resistance to extinction in the UI procedure may represent an attempt to establish an alternative contingent source of reinforcement when, in fact, none exists.

The punishment procedure, while eliminating the avoidance contingency, establishes an alternative contingent relationship to prevent the US from occurring (i.e., the nonresponse contingency). The acquisition of this alternative contingent source of reinforcement is considered to be facilitated by the previously established avoidance contingency. Once the avoidance contingency is eliminated as a source of reinforcement, the acquisition of the nonresponse contingency and, hence, resistance to punished extinction will vary as a function of the extent to which the extinction conditions enhance the establishment of this contingent relationship (e.g., Moffat \& Koch, 1974).

Thus, resistance to extinction is interpreted to be a function of the extent to which the avoidance contingency can be maintained and/or the extent to which this acquired contingency facilitates or inhibits the acquisition of the alternative contingent source of reinforcement. While the results of the present experiment and other studies (e.g., Bolles et al, 1971; Meyer, 1970) conform to this interpretation, further research is necessitated in order to confirm its validity.

\section{REFERENCES}

Bolles, R. C. Species-specific defense reactions and avoidance learning. Psychological Review, 1970, 77, 32-48.

Bolles, R. C., Moot, S., \& Grossen, N. E. The extinction of shuttlebox avoidance. Learning \& Motivation, 1971, 2, 324-333.

Davenport, D., \& Olson, R. A reinterpretation of extinction in discriminated avoidance. Psychonomic Science, 1968, 13, 5-6.

Hartley, D. Sources of reinforcement in learned avoidance. Journal of Comparative \& Physiological Psychology, 1968,66 12-16.

Meyer, P. Role of an unavoidability procedure in eliminating avoidance behavior with humans. Journal of Experimental Psychology, 1970, 86, 337-340.

Moffat, G. H. Avoidance conditioning in young children with interruption of a positive stimulus as the aversive event. Journal of Experimental Child Psychology, 1972, 12, 21-28.

Moffat, G. H., \& Koch, D. L. Effect of delay and duration of punished extinction following avoidance conditioning. Psychological Reports, 1974, 34,779-784.

Moffat, G. H., \& Miller, F. D. Effect of pretraining and instructions on avoidance conditioning in preschool children. Journal of Experimental Child Psychology, 1971, 11, 133-138.

Siegel, S. Nonparametric statistics. New York: McGraw-Hill, 1956.

Seligman, M. E. P., Maier, S., \& Solomon, R. L. Unpredictable and uncontrollable aversive events. In R. Brush (Ed.), Aversive conditioning and learning. New York: Academic Press, 1971 Pp. 347-400.

Winer, B. J. Statistical principles in experimental design. (2nd ed.) New York: McGraw-Hill, 1971.

(Received for publication April 10, 1974.) 